\title{
COMPARTIMENTAÇÃO GEOMORFOMÉTRICA DA BACIA HIDROGRÁFICA DO RIO JAGUARI - OESTE DO RS
}

Vinicius Silveira dos Santos ${ }^{1}$ Luís Eduardo de Souza Robaina ${ }^{2}$ Romario Trentin ${ }^{3}$

Resumo: O relevo está em constantes transformações decorrentes dos agentes e processos naturais. O Modelo Digital do Terreno (MDT) surge como ferramenta importante na obtenção das informações altimétricas do relevo, possibilitando uma análise automatizada que possibilitem interpolações de variáveis pré-definidas. 0 presente trabalho traz como objetivo a compartimentação geomorfométrica da Bacia Hidrográfica do Rio Jaguari a partir da árvore de decisão e a interpolação de dados referentes a morfometria do relevo, realizando-se a correlação dos dados topográficos (altitude, declividade, perfil de curvatura e plano de curvatura) gerados em ambiente de SIG. Foram definidas 18 (dezoito) unidades geomorfométricas, que possibilitaram a análise do comportamento de fluxo e dos processos erosivos nas vertentes.

Palavras-chave: Geomorfometria. MDT. SIG. Rio Jaguari. Relevo.

\section{GEOMORPHOMETRIC COMPARTMENTATION OF THE WATER CATCHMENT AREA OF THE RIVER JAGUARI - WEST OF RS}

Abstract: The relief is in constant transformation due to natural agents and processes. The Digital Terrain Model (MDT) emerges as an important tool in obtaining the altimetric information of the relief, enabling an automated analysis that allow interpolations of pre-defined variables. The present study aims at geomorphometric compartmentation of the Jaguari River Hydrographic Basin from the decision tree and interpolation of data related to relief morphometry, by correlating the topographic data (altitude, slope, curvature profile and plane of curvature) generated in a GIS environment. Eighteen (18) geomorphometric units were defined, which enabled the analysis of the flow behavior and erosive processes in the slopes.

Keywords: Geomorphometry. MDT. GIS. Jaguari River. Relief.

\section{COMPARTIMENTACIÓN GEOMORFOMÉTRICA DE LA CUENCA HIDROGRÁFICA DEL RÍO JAGUARI - OESTE DE RS}

Resumen: El relieve se encuentra en constante transformación debido a los agentes y procesos naturales. El Modelo Digital del Terreno (MDT) surge como una herramienta importante en la obtención de la información altimétrica del relieve, permitiendo un análisis automatizado que permite interpolar variables predefinidas.

\footnotetext{
${ }^{1}$ Universidade Federal de Santa Maria, Programa de Pós-graduação em Geografia, Santa Maria, Brasil, viniciusgeografia93@gmail.com, https://orcid.org/0000-0001-8970-6357

2 Universidade Federal de Santa Maria, Departamento de Geociências, Santa Maria, Brasil, lesrobaina@yahoo.com.br, https://orcid.org/0000-0002-2390-6417

${ }^{3}$ Universidade Federal de Santa Maria, Departamento de Geociências, Santa Maria, Brasil, romario.trentin@gmail.com, https://orcid.org/0000-0002-0615-2801
} 
El presente estudio tiene como objetivo la compartimentación geomorfométrica de la Cuenca Hidrográfica del Río Jaguari a partir del árbol de decisión y la interpolación de datos relacionados con la morfometría en relieve, Se realiza la correlación de los datos topográficos (altitud, pendiente, perfil de curvatura y plano de curvatura) generados en un entorno GIS. Se definieron dieciocho (18) unidades geomorfométricas, que permitieron analizar el comportamiento del flujo y los procesos erosivos en los taludes.

Palabras clave: Geomorfometría. MDT. GIS. Río Jaguari. Relieve.

\section{Introdução}

No passar dos anos, a evolução tecnológica intensificou-se e consequentemente houve um grande aumento no uso das novas ferramentas, em diversos ramos da sociedade. Não diferente disso, o uso das tecnologias nos trabalhos acadêmicos, ganharam destaque.

Concomitante a isso, os estudos ambientais vêm se aprimorando no manuseio de novos softwares que possam auxiliar em levantamentos de dados e consequentemente na interpolação dos mesmos, para que se obtenha resultados mais precisos.

Os estudos ambientais contribuem ao planejamento ambiental, sendo este um dos objetos de estudo da Geografia, pois visa conciliar o uso de recursos naturais de modo ordenado, sem que a ação antrópica possa ser capaz de alterar as características naturais da paisagem.

Para contribuir nesse processo de utilizar-se de ferramentas que contribua na identificação de problemas ambientais e propor técnicas de conservação e controle, a partir de dados geográficos espacializados, surgem as geoctecnologias.

Os mapeamentos geomorfológicos, utilizam-se das novas ferramentas disponibilizadas pelas geotecnologias, que trouxeram no decorrer dos anos, a criação de novas metodologias que atendessem aos interesses do pesquisador, mas que também, representassem o mais fiel possível, as condições naturais do relevo.

O relevo pode ser considerado como a superfície em que ocorre a interação entre o homem e a natureza, apresentando-se como temática fundamental para estudos ambientais, sendo o elemento caracterizador da paisagem, pois passa por constantes transformações, sendo estas alterações de origem natural (terremotos, vulcões, erosão) ou de origem antrópica.

Ross (2008), aborda o relevo como fruto da atuação de duas forças opostas a endógena (interna) e a exógena (externa), sendo que as internas são as geradoras 
das grandes formas estruturais do relevo e as externas são as responsáveis pelas formas esculturais.

Segundo Vasconcelos et al (2012), as feições do relevo inferem sobre as dinâmicas que controlam a distribuição espacial dos materiais e energia, como: regime da dinâmica da água, textura do solo, presença de sedimentos inconsolidados, desenvolvimento pedogenético, entre outros.

Assim, há muitos estudos com o intuito de obtenção e descrição mais detalhada das formas do terreno, com o propósito de compreender a evolução da paisagem. Nesse contexto de análise, surge a ciência denominada de (Geo) morfometria, que analisa a superfície topográfica de modo quantitativo.

Em estudos recentes sobre a temática, alguns autores propõem métodos de análises rápidas e precisas, através de técnicas de geoprocessamento e o uso de MDE's (Modelos Digitais de Elevação), por exemplo, utilizando-se de variáveis topográficas pré-definidas, para entender a atuação e intensidade em que os processos erosivos veem atuando sobre a superfície terrestre. Os MDE's auxiliam em diferentes abordagens nos estudos geomorfológicos recentes, como no trabalho desenvolvido por Ippoliti et al (2005), que utilizando-se do MDE identificaram unidades de solos pelas geoformas e pedoforma na bacia hidrográfica em análise, por meios de atributos topográficos.

Silveira (2010), ao desenvolver seu trabalho sobre a caraterização preliminar de solos a partir de um MDT, propôs o cruzamento de dados altimétricos como a hipsometria, declividade, plano de curvatura e perfil de curvatura, servindo de base para estudos voltados à geomorfometria.

Nessa perspectiva, o MDE como ferramenta de análise da superfície terrestre, pode ser definido como a representação matemática de determinada superfície, através das coordenadas X, Y e Z (Rocha, 2000). A geomorfometria a partir de uma proposta de análise digital do terreno, atendendo a abordagem geomorfológica, faz uso de equações matemáticas para a descrição das formas do relevo, trazendo uma nova forma de análise.

Assim, a geomorfometria pode ser entendida como uma descrição numérica da superfície terrestre, tornando-se como uma fonte de informação mais confiável para a descrição de determinados fenômenos, como por exemplo: hidrogramas de bacias hidrográficas, erosão do solo, movimento de massa, fluxo de água, entre outros (Vasconcelos et al, 2012). O uso de parâmetros geomorfométricos em pesquisas científicas, voltadas aos estudos ambientais, aderem agilidade e precisão 
nas metodologias, ao propor métodos de prevenção aos agentes erosivos, por exemplo, devido a evolução das técnicas computacionais e matemáticas (Sccoti, 2015).

O presente trabalho traz como objetivo, realizar a compartimentação geomorfométrica da Bacia Hidrográfica do Rio Jaguari (BHRJ), localizada no Oeste do Estado do Rio Grande do Sul, a partir do mapeamento geomorfométrico automatizado de Iwahashi e Pike (2007), e baseando-se nos resultados experimentais proposto por Silveira et al (2014a) no Estado do Paraná.

Trentin et al (2015) destaca a compartimentação do relevo com grande potencial de emprego em distintas aplicações como estudos de planejamento e gestão territorial, zoneamentos ambientais, cartografia geomorfológica, pedológica, de suscetibilidade geoambiental, dentre outras. Com as técnicas computacionais, é possível realizar uma análise quantificada e automatizada do relevo, contribuindo aos estudos voltados a entender a dinâmica em que os agentes modeladores do relevo atuam.

Assim, os SIG's (Sistema de Informações Geográficas), surgem como ferramenta auxiliar para análise digital do terreno, sendo um sistema automatizado capaz de coletar dados de diversas fontes, com o objetivo de gerar informações que possam atender as diferentes pesquisas que a ciência geográfica se propõe a estudar.

\section{Área de estudo}

A BHRJ está localizada na região oeste do Estado do Rio Grande do Sul (Figura 1), com uma área aproximada de $5.149,73 \mathrm{~km}^{2}$, tendo sua extensão distribuída por 11 municípios: Jaguari, Jari, Jóia, Mata, Nova Esperança do Sul, Santiago, São Francisco de Assis, São Miguel das Missões, São Vicente do Sul, Toropi e Tupanciretã.

O rio Jaguari é um dos principais afluentes da região Oeste, do rio lbicuí, pois o rio Jaguari além de apresentar grande extensão, passa por diversas porções geomorfológicas do Estado. A BHRJ distribui-se por uma extensa área territorial do Rio Grande do Sul, possibilitando analisar a partir das diferentes formas do relevo, o comportamento das encostas, e assim poder expandir nos estudos geomorfológicos, o uso das geotecnologias. 
Figura 01 - Mapa de Localização da Bacia Hidrográfica do Rio Jaguari

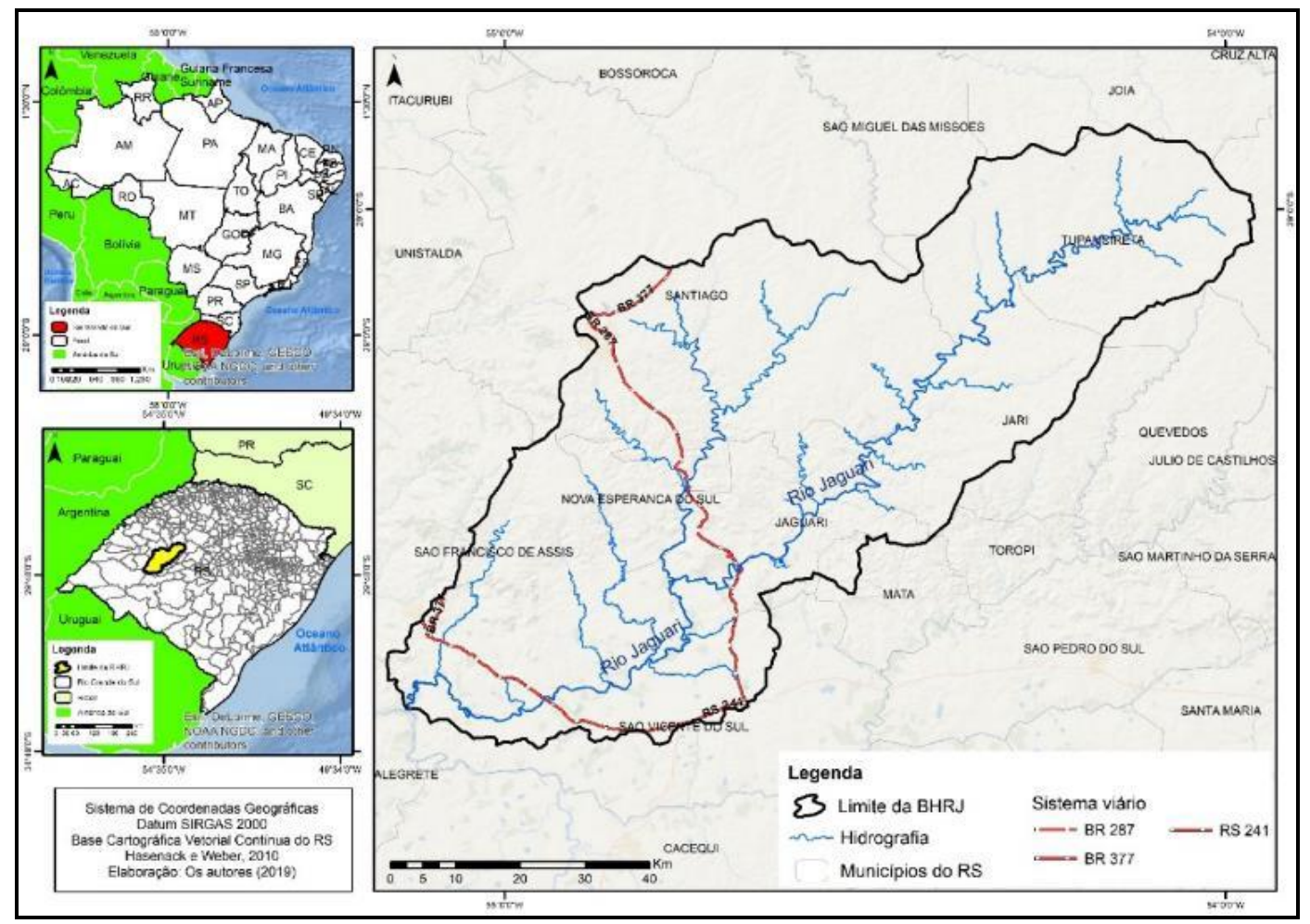

Fonte: Os autores.

\section{Metodologia}

O levantamento e processamento cartográfico para o desenvolvimento do presente trabalho, deu-se em ambiente de SIG (Sistema de Informação Geográfica), sob a interface do software ArcGis versão 10.1.

$\mathrm{Na}$ elaboração do mapeamento geomorfométrico na BHRJ, utilizou-se a proposta de Iwahashi e Pike (2007) e Silveira \& Silveira (2013), estabelecendo-se uma árvore de decisão para a definição das unidades geomorfométricas. Para isso, é necessário a interpolação de quatro parâmetros topográficos: altimetria, declividade, plano de curvatura e perfil de curvatura.

Para a definição do valor altimétrico maior/menor que a média, deu-se através do histograma de frequência gerado pelo SIG (Figura 02), assim como a caracterização das declividades e as formas das encostas (plano de curvatura e perfil de curvatura). 
Figura 02 - Histograma de frequência referente aos parâmetros topográficos na BHRJ

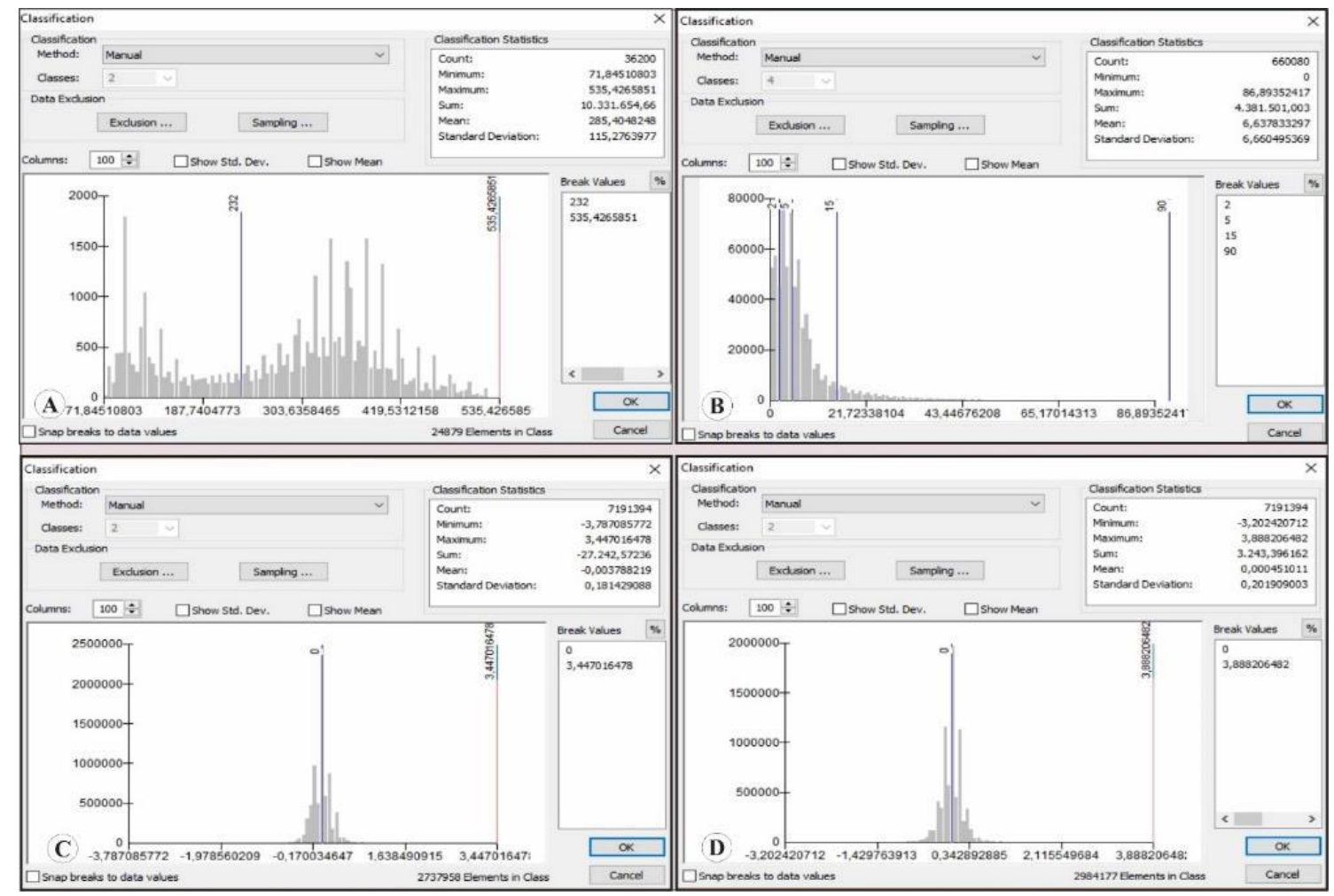

Fonte: Os autores. A- hipsometria; B- declividade; C- plano de curvatura; D- perfil de curvatura.

Conforme o histograma de frequência apresentado, a altitude (A) apresenta uma média de 231,79 metros, sendo adotado para o trabalho, o valor arredondado de 232 metros. Considerou-se que os valores acima da média representam o alto curso da BHRJ e valores inferiores à média como o baixo curso da bacia hidrográfica. Os dados referentes à declividade $(B)$, foram classificados em três classes: $<5 \%$, de 5 a $15 \%$ e $>15 \%$, sendo que as mesmas, destacam as diferentes formas do relevo na área de estudo, marcando a geomorfologia da BHRJ.

O plano de curvatura $(C)$ definiu-se a partir da delimitação dos valores em duas classes, sendo: $1^{\text {a }}$ classe Convergente $(-0,99236536$ a 0$) ; 2^{\underline{a}}$ classe Divergente (0 a 1,283188696). O perfil de curvatura (D), utilizando o mesmo método de delimitação do plano de curvatura, deu - se em duas classes, sendo: $1^{\text {a }}$ classe Convexo $(-1,344539404$ a 0$) ; 2^{a}$ classe (0 a 1,27937633). O plano de curvatura corresponde a variação do gradiente de arqueamento na direção ortogonal da vertente, enquanto o perfil de curvatura refere-se a taxa de variação do gradiente de arqueamento na direção da sua orientação, sendo decisiva na aceleração ou desaceleração do fluxo da água. Na elaboração deste trabalho, optou-se pela classificação das formas de vertentes em dois modos: quanto ao plano de curvatura divergente/convergente; quanto ao perfil de curvatura côncava/convexa. 
Após o processamento das informações referentes aos parâmetros topográficos, possibilitou-se a elaboração da árvore de decisão (Figura 3), que auxiliou na definição das unidades geomorfométricas. No cruzamento das informações, foi possível estabelecer as 24 unidades, sendo que, 6 unidades não apresentaram representatividade espacial, sendo agrupadas às unidades com características semelhantes.

A Tabela 01 apresenta os valores estabelecidos no SIG, para a interpolação dos parâmetros topográficos.

Tabela 1 - Parâmetros topográficos que caracterizam as unidades geomorfométricas determinadas na BHRJ.

\begin{tabular}{c|c|c|c}
\hline Altitude & Declividade & Plano & Perfil \\
\hline $1-<$ média & $1-<5 \%$ & 1 - Convergente & 1 - Convexo \\
\hline $2->$ média & $2-5$ a $15 \%$ & 2 - Divergente & 2 - Côncavo \\
\hline- & $3->15 \%$ & - & - \\
\hline
\end{tabular}

Elaboração: Os autores 
Figura 03 - Fluxograma apresentando a árvore de decisão utilizada para a definição das unidades geomorfométricas

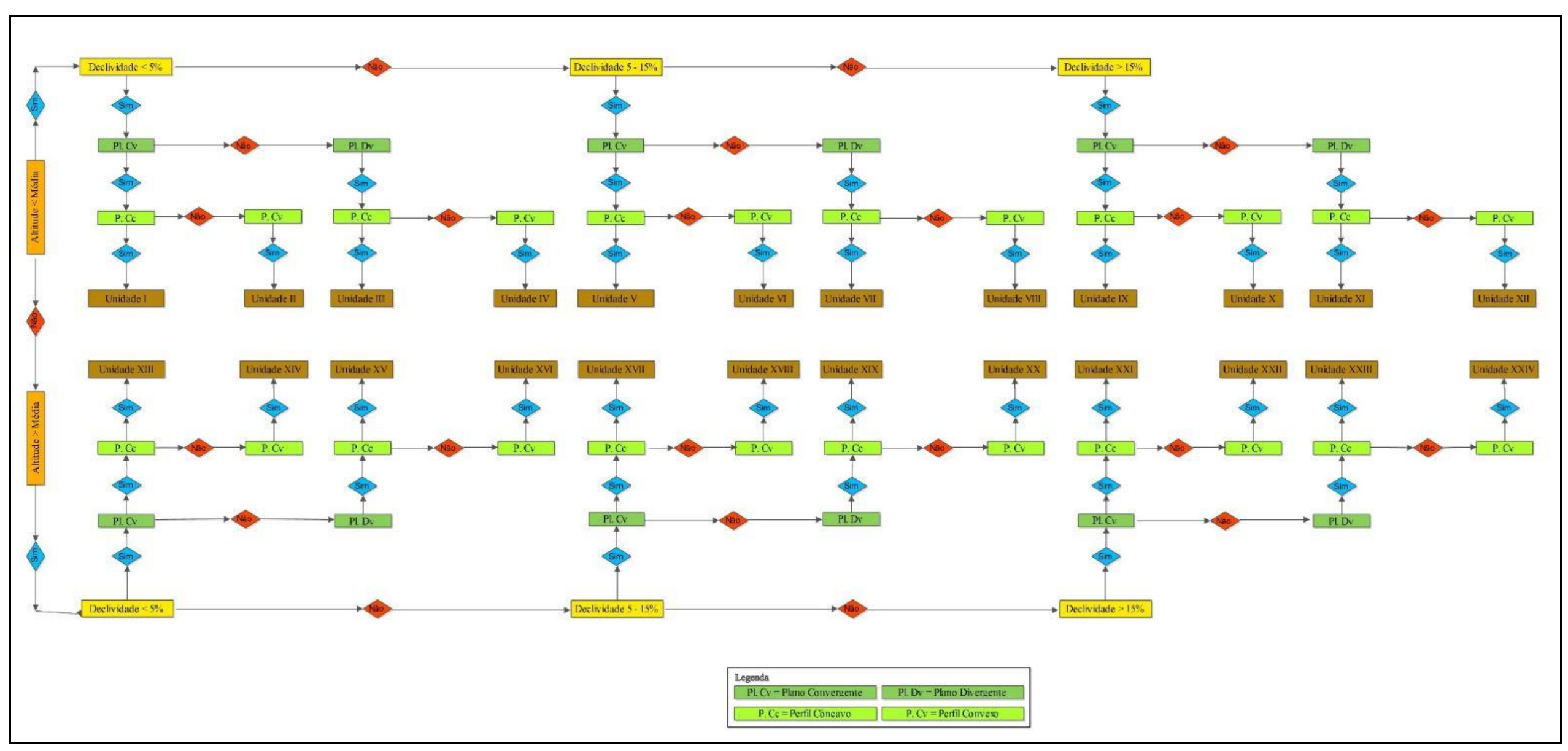

Fonte: Os autores. 
As formas de curvaturas interpoladas para o presente trabalho, deu-se através do emprego do polinômio de Zevenbergen e Thorne (1987). Para a caracterização das unidades geomorfométricas da BHRJ, optou-se por agrupamentos de unidades, levando se em consideração o plano de curvatura das unidades e também pela representatividade (área) na BHRJ. As unidades agrupadas na altitude menor que a média: Unidades I e II (Unidade I), Unidades V e VI (Unidade IV) e Unidades IX e X (Unidade VII). As unidades agrupadas nas altitudes superiores à média: Unidades XIII e XIV (Unidade X), Unidades XVII e XVIII (Unidade XIII) e Unidades XXI e XXII (Unidade XVI). No agrupamento das unidades geomorfométricas, definiu-se um total de 18 unidades para a análise.

\section{Resultados}

A BHRJ apresenta uma área de 5.149,73 km², distribuindo-se por onze municípios da região oeste do estado do Rio Grande do Sul. O rio Jaguari, um dos afluentes principais do Rio lbicuí, tem o seu canal principal, conforme a classificação de Strahler (1952), de 6 ${ }^{\mathbf{a}}$ ordem e a distribuição dos canais fluviais apresenta um padrão, predominantemente, retangular devido ao controle de falhas e fraturas.

A área de estudo, apresenta amplitude altimétrica de 464 metros, tendo como menor cota altimétrica de 71 metros (próximo ao encontro entre o rio Jaguari e o rio Ibicuí) e maior cota altimétrica de 535 metros (situadas ao Norte da BHRJ), obtendo como média altimétrica, a cota de 232 metros. As declividades superiores a 5\%, marcam o limite para a ocorrência dos processos erosivos no relevo, ou seja, vertentes com altos declives estão sujeitas a processos denudacionais, enquanto que os baixos declives ( $<5 \%$ ) estão propícios a processos agradacionais.

Analisando-se as declividades do relevo na BHRJ (Figura 04), pode-se identificar as porções do relevo, que marcam a zona de transição entre o Planalto Meridional e a Depressão Periférica. 
Figura 04 - Mapa de Declividade da BHRJ.

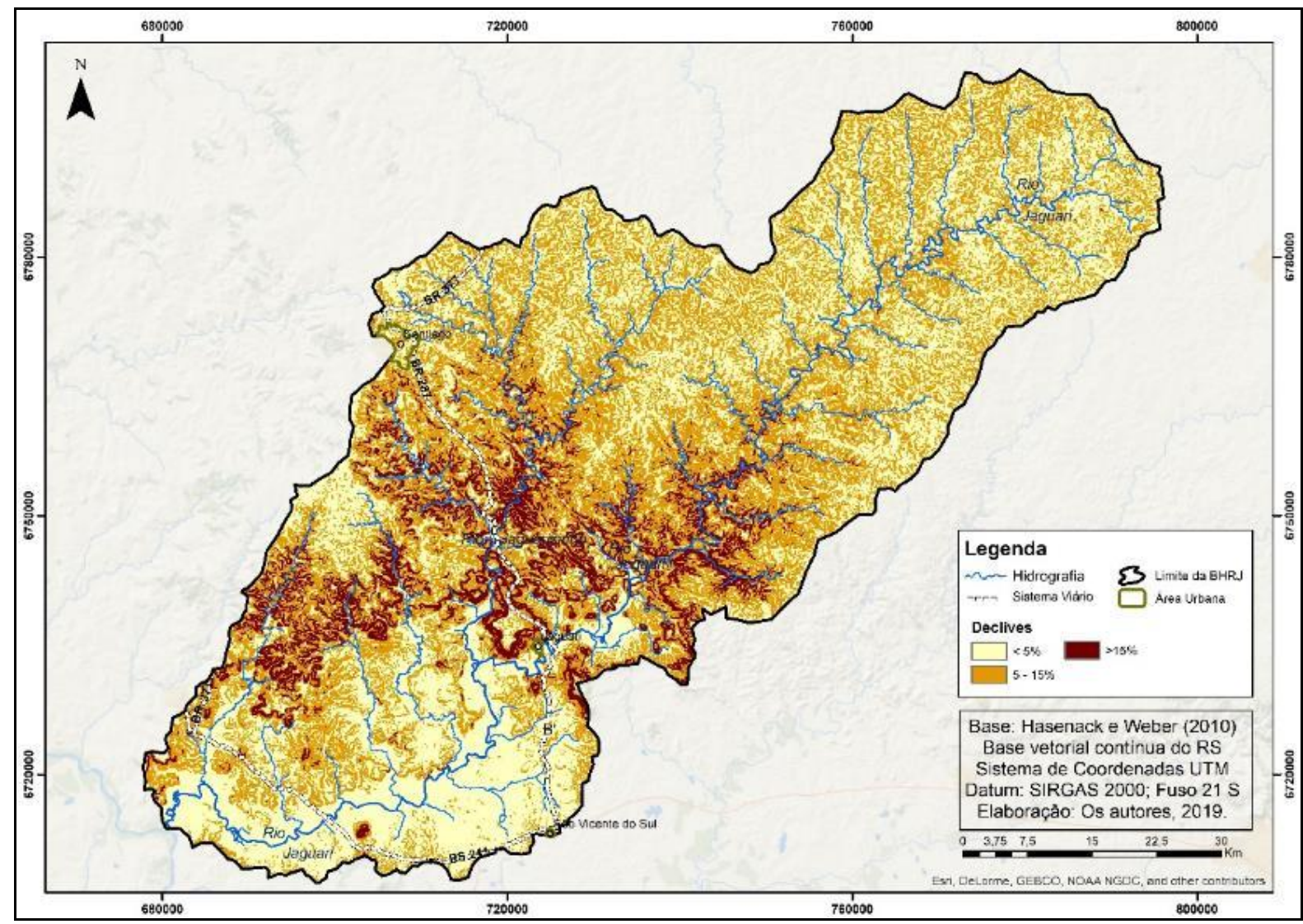

Fonte: Os autores.

Conforme a proposta estabelecida na árvore de decisão, a partir da interpolação dos parâmetros topográficos, definiu-se as 18 unidades geomorfométricas, caracterizadas espacialmente na Tabela 02.

Tabela 02 - Caracterização das unidades geomorfométricas da BHRJ

\begin{tabular}{c|c|c}
\hline Unidade & Área $\left.\mathbf{( k m}^{2}\right)$ & Porcentagem (\%) \\
\hline I & 469,48 & 9,11 \\
\hline II & 92,31 & 1,79 \\
\hline III & 179,53 & 3,48 \\
\hline IV & 321,91 & 6,25 \\
\hline V & 115,41 & 2,24 \\
\hline VI & 198,98 & 3,86 \\
\hline VII & 110,01 & 2,13 \\
\hline VIII & 55,87 & 1,16 \\
\hline IX & 77,78 & 1,51 \\
\hline X & 618,98 & 12,01 \\
\hline XI & 171,75 & 3,33 \\
\hline
\end{tabular}




\begin{tabular}{c|c|c}
\hline XII & 369,17 & 7,16 \\
\hline XIII & 918,92 & 17,84 \\
\hline XIV & 287,36 & 5,58 \\
\hline XV & 690,06 & 13,39 \\
\hline XVI & 193,73 & 3,76 \\
\hline XVII & 89,61 & 1,74 \\
\hline XVIII & 188,87 & 3,66 \\
\hline
\end{tabular}

Elaboração: Os autores

As unidades de I a IX representam as que ocorrem em altitudes inferiores a 234 metros, compondo as porções do baixo curso da bacia hidrográfica (Tabela 03).

Tabela 03 - Caracterização das Unidades Geomorfométricas- Unidade I a Unidade IX

\begin{tabular}{c|c|c|c|c}
\hline Unidade & Altitude & Declividade & Plano & Perfil \\
\hline I & $<232 \mathrm{~m}$ & $<5 \%$ & Convergente & Convexo - Côncavo \\
\hline II & $<232 \mathrm{~m}$ & $<5 \%$ & Divergente & Côncavo \\
III & $<232 \mathrm{~m}$ & $<5 \%$ & Divergente & Convexo \\
\hline IV & $<232 \mathrm{~m}$ & $5-15 \%$ & Convergente & Convexo - Côncavo \\
\hline V & $<232 \mathrm{~m}$ & $5-15 \%$ & Divergente & Côncavo \\
\hline VI & $<232 \mathrm{~m}$ & $5-15 \%$ & Divergente & Convexo \\
\hline VII & $<232 \mathrm{~m}$ & $>15 \%$ & Convergente & Convexo - Côncavo \\
\hline VIII & $<232 \mathrm{~m}$ & $>15 \%$ & Divergente & Côncavo \\
\hline IX & $<232 \mathrm{~m}$ & $>15 \%$ & Divergente & Convexo \\
\hline
\end{tabular}

Elaboração: Os autores

A Unidade I possui uma área de 469,48 $\mathrm{km}^{2}$, representando 9,11\% da BHRJ. A unidade caracteriza-se por ocorrer em encostas que apresentam fluxo hídrico convergente, com declives inferiores a 5\%. Sua distribuição espacial se dá no baixo curso da BHRJ, caracterizando a forma da encosta quanto ao perfil tanto convexa quanto côncavo, o que marca a concentração de fluxo d'água em uma velocidade baixa, associando-se junto ao leito do rio Jaguari próximo à foz.

A Unidade II caracteriza-se por declives inferiores a $5 \%$, sendo o plano de curvatura divergente e o perfil de curvatura côncavo. Nessas condições quanto à forma, há dispersão de fluxo na encosta e deposição de materiais em meia encosta. 
A Unidade II apresenta área de $92,31 \mathrm{~km}^{2}$, representando $1,79 \%$ da área total da BHRJ.

A Unidade III apresenta-se com declives inferiores a 5\%, caracterizando quanto ao plano de curvatura divergente e ao perfil de curvatura convexo. $A$ unidade caracteriza-se pela dispersão no fluxo no topo de divisores d'água, acarretando em uma maior capacidade de carregamento de matérias. A unidade apresenta área de $179,53 \mathrm{~km}^{2}$, representando $3,48 \%$ da totalidade.

A Unidade IV apresenta-se em declives entre 5-15\%, sendo o plano de curvatura convergente e o perfil de curvatura tanto convexo quanto côncavo. A unidade caracteriza-se pela concentração de fluxo na encosta, influenciando na atuação dos processos erosivos na encosta. A unidade possui área de $321,91 \mathrm{~km}^{2}$, representando $6,25 \%$ da área total.

A Unidade $V$ apresenta- se em declives que variam entre 5-15\%, tendo 0 plano de curvatura divergente e o perfil de curvatura côncavo. Essa unidade distribui-se próximos aos divisores da água, influenciando na intensidade do escoamento na vertente. A unidade apresenta área de $115,41 \mathrm{~km}^{2}$, representando $2,24 \%$ da BHRJ.

A Unidade VI com declives que variam entre 5-15\%, com plano de curvatura divergente e perfil de curvatura convexo, apresenta área de 198,98 km² representando $3,86 \%$ da área total. A unidade está associada próximo ao topo da vertente, acarretando em um escoamento de fluxo moderado, em um perfil da encosta acidentado, com uma grande capacidade de transporte de matérias decorrentes dos processos erosivos.

A Unidade VII apresenta-se em declives superiores a 15\%, com plano de curvatura convergente e perfil de curvatura tanto convexo quanto côncavo. A unidade distribui-se região próxima à região de quebra do relevo (declividades superiores a 15\%), o que acarreta na concentração do fluxo vindo da região de transição, ou seja, da área mais alta para a mais baixa. A unidade apresenta área de $110,01 \mathrm{~km}^{2}$, representando $2,13 \%$ da área total.

A Unidade VIII apresenta-se com declives superiores a $15 \%$, com o plano de curvatura divergente e o perfil de curvatura côncavo. A unidade distribui-se em porções do relevo encaixado, marcando o divisor de água, estando os canais fluviais com fluxo acentuado, influenciando no transporte de materiais das encostas para dentro dos leitos. A unidade apresenta área de $55,87 \mathrm{~km}^{2}$ representando $1,16 \%$ da área total. 
A Unidade IX com plano de curvatura divergente e perfil de curvatura convexo, apresenta-se em declives superiores a 15\%. A unidade caracteriza-se pelo acumulo do fluxo e na intensidade do transporte de materiais para o canal fluvial. A unidade área de $77,78 \mathrm{~km}^{2}$, representando $1,51 \%$ da BHRJ.

A representação gráfica das unidades geomorfométricas I a IX, podem ser analisadas na Figura 05.

Figura 05 - Mapa Geomorfométrico da BHRJ, representando a Unidade I à IX.

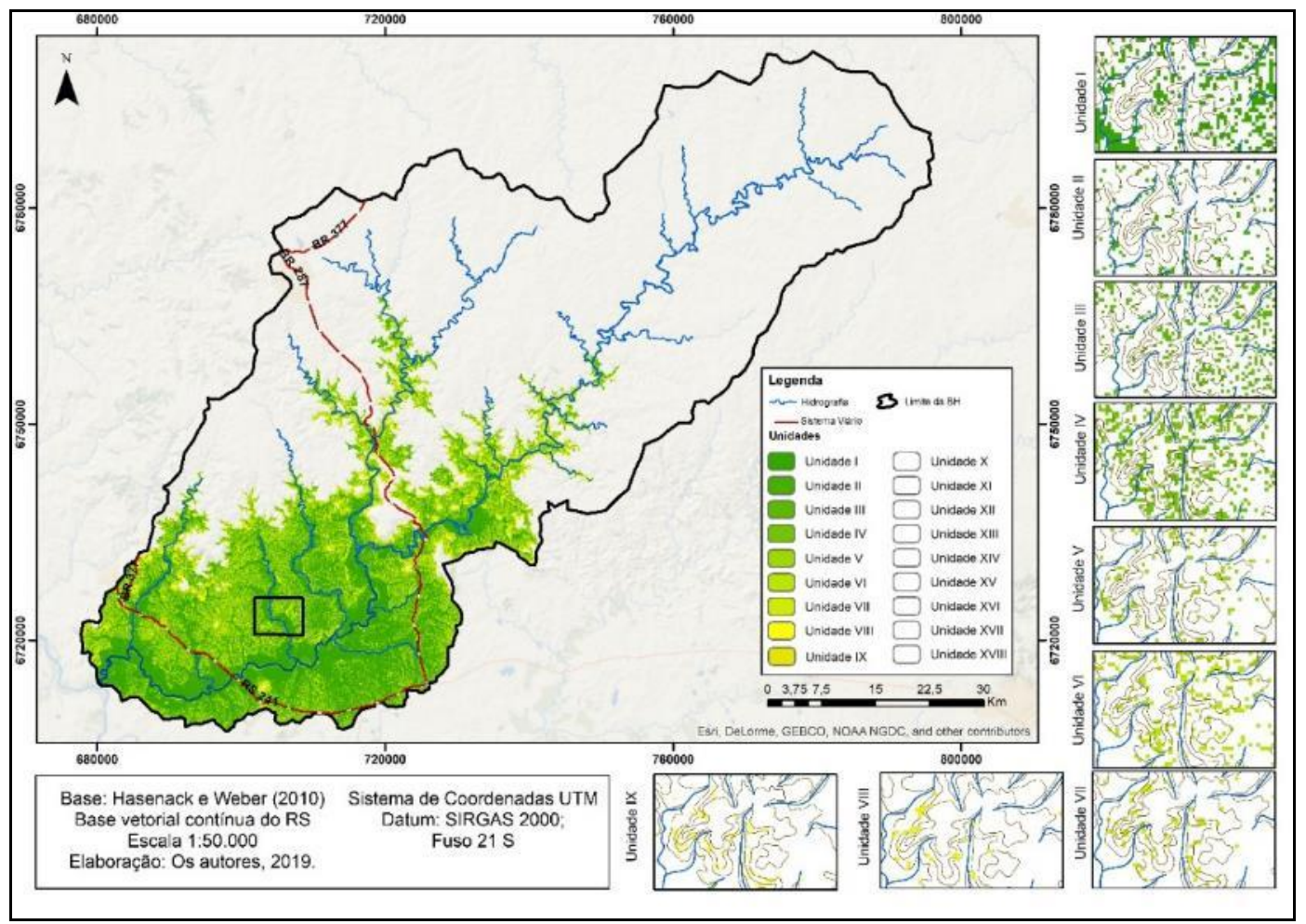

Fonte: Os autores.

Na Figura 06, visualiza-se a presença de capões de eucaliptos utilizados em pequenas propriedades, na porção do Baixo Jaguari. Nas altitudes inferiores a 234 metros, há o predomínio dos campos e a prática da atividade pecuarista, sobre essa porção na BHRJ. 
Figura 06 - Uso do solo na porção do Baixo Jaguari

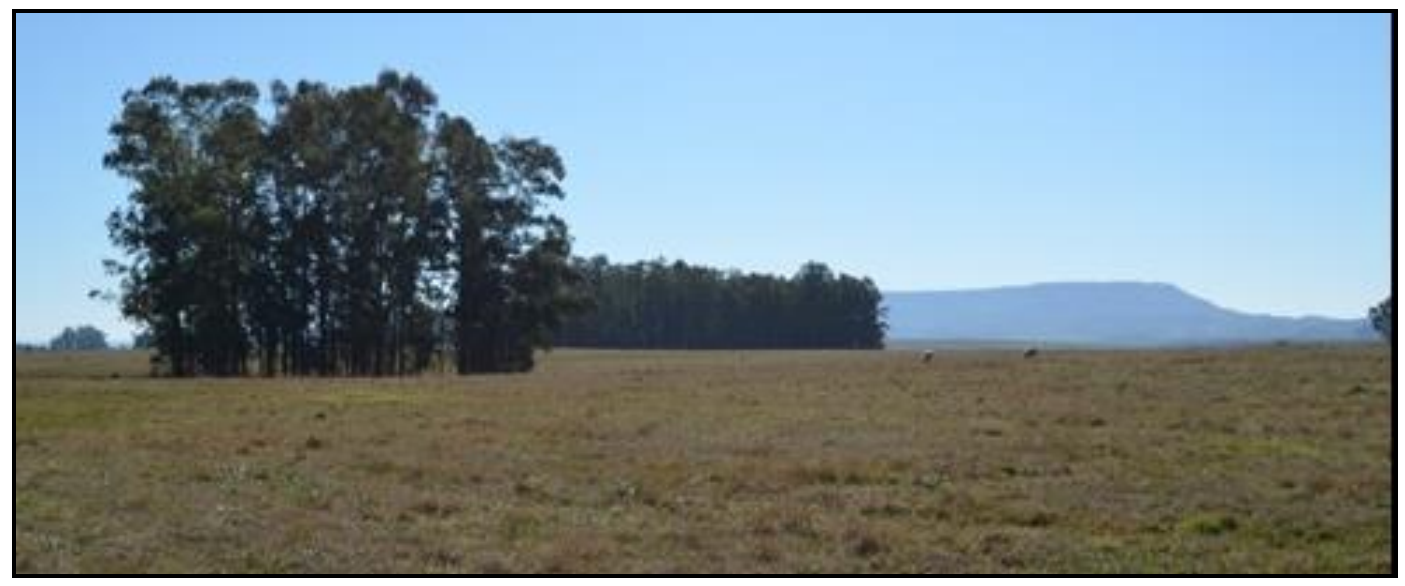

Fonte: Os autores. Coordenadas: S29³6'20.04"; W54²41'17.13"; Localidade: São Vicente do Sul-RS.

Da Unidades X à Unidade XVIII, apresentam altitudes superiores à média, caracterizando as áreas do alto curso da BHRJ (Tabela 04).

Tabela 04 - Caracterização das Unidades Geomorfométricas- Unidade X a Unidade XVIII

\begin{tabular}{c|c|c|c|c}
\hline Unidade & Altitude & Declividade & Plano & Perfil \\
\hline $\mathrm{X}$ & $>232 \mathrm{~m}$ & $<5 \%$ & Convergente & Convexo - Côncavo \\
\hline $\mathrm{XI}$ & $>232 \mathrm{~m}$ & $<5 \%$ & Divergente & Côncavo \\
\hline $\mathrm{XII}$ & $>232 \mathrm{~m}$ & $<5 \%$ & Divergente & Convexo \\
\hline XIII & $>232 \mathrm{~m}$ & $5-15 \%$ & Convergente & Convexo - Côncavo \\
\hline $\mathrm{XIV}$ & $>232 \mathrm{~m}$ & $5-15 \%$ & Divergente & Côncavo \\
\hline $\mathrm{XV}$ & $>232 \mathrm{~m}$ & $5-15 \%$ & Divergente & Convexo \\
\hline $\mathrm{XVI}$ & $>232 \mathrm{~m}$ & $>15 \%$ & Convergente & Convexo - Côncavo \\
\hline $\mathrm{XVII}$ & $>232 \mathrm{~m}$ & $>15 \%$ & Divergente & Côncavo \\
\hline XVIII & $>232 \mathrm{~m}$ & $>15 \%$ & Divergente & Convexo \\
\hline
\end{tabular}

Elaboração: Os autores

A Unidade $\mathrm{X}$ apresenta-se distribuída pela porção de médio à alto curso da BHRJ, com declives inferiores a $5 \%$. Com o plano de curvatura convergente e o perfil de curvatura tanto convexo quanto côncavo, apresentando área de 618,98 km², representando $12,01 \%$ da área total.

A Unidade XI apresenta declive inferior a $5 \%$ com plano de curvatura divergente e o perfil de curvatura côncavo. A unidade distribui-se associado aos canais fluviais, onde que o fluxo de água é disperso para os canais, ocorrendo 
transporte e deposição de sedimentos. A unidade tem área de $171,75 \mathrm{~km}^{2}$, representando 3,33\% da BHRJ.

A Unidade XII com plano de curvatura divergente e perfil de curvatura convexo, apresenta-se em declive inferior a 5\%. A unidade distribui-se expressivamente no alto curso da BRHJ, sobre o divisor d'água, fazendo com que haja dispersão do fluxo e aumento no escoamento superficial na encosta. $A$ unidade apresenta área de $369,17 \mathrm{~km}^{2}$, representando $7,16 \%$ da área total.

A Unidade XIII apresenta com uma área de $918,92 \mathrm{~km}^{2}$, representando $17,84 \%$ da área total, com plano de curvatura convergente e perfil de curvatura tanto convexo quanto côncavo, e declives variando de 5 a 15\%. A unidade distribui-se no média ao alto curso da bacia hidrográfica, em regiões de topo de colinas próximo a cabeceira de drenagem.

A Unidade XIV com declives entre 5-15\% e plano de curvatura divergente e perfil de curvatura côncavo, apresenta área de $287,36 \mathrm{~km}^{2}$, representando $5,58 \%$ da área total da BHRJ. Distribuindo-se no médio e alto curso da bacia hidrográfica, a unidade situa-se próximo a meia vertente, fazendo com que haja deposição de sedimentos na encosta, influenciada pela forma e declividade.

A Unidade XV distribui-se em declives entre 5-15\%, com plano de curvatura divergente e o perfil de curvatura convexo. A unidade caracteriza-se próximo à topos de colinas, fazendo com que haja grande dispersão de fluxo e atuação dos processos erosivos. A unidade apresenta área de 690,06 km² representando $13,39 \%$ da área total. Podem ser visualizadas, na Figura 07, as unidades geomorfométricas $\mathrm{X}$ a XV.

Nas altitudes superiores à média na BHRJ, destaca-se o uso do solo para plantações como a soja, trigo, pastagens e, a presença de campos nativos (Figura 08).

Nessa porção da BHRJ, a presença de gramíneas acaba contribuindo em uma maior absorção da água, o que acarreta na diminuição do fluxo d'água nas cabeceiras de drenagem. 
Figura 07 - Mapa Geomorfométrico da BHRJ, representando a Unidade X à XV.

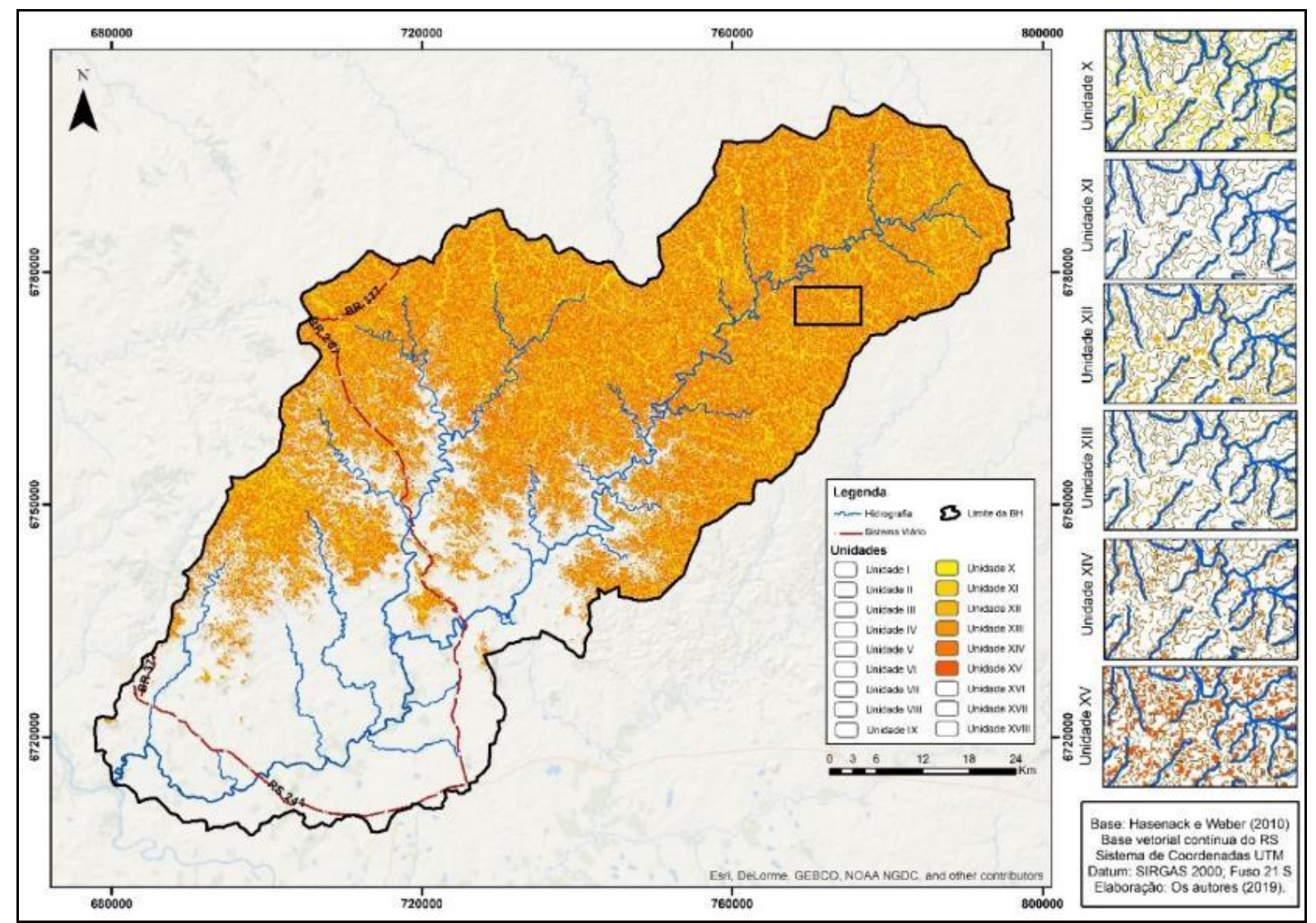

Fonte: Os autores.

Figura 08 - Uso do solo na porção do Alto Jaguari

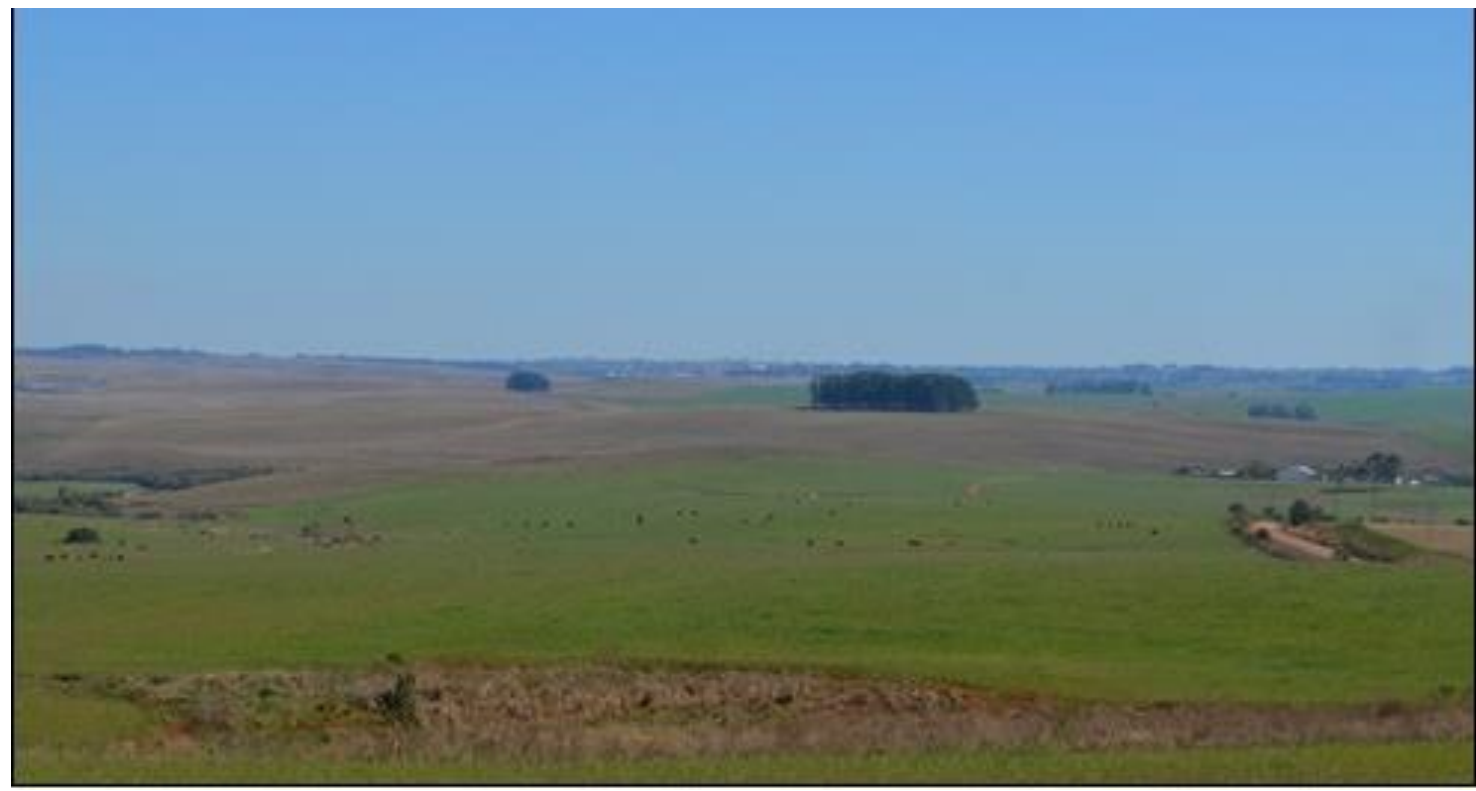

Fonte: Os autores. Coordenadas: S297'6.48"; W54²4'24.47"; Localidade: Santiago-RS

As Unidade $\mathrm{XVI}, \mathrm{XVII}$ e XVIII destacam a geomorfologia de transição na BHRJ, sendo da região Planalto Meridional para a Depressão Periférica no Estado gaúcho. 
A Unidade XVI caracteriza-se pelo plano de curvatura convergente e o perfil de curvatura tanto convexo quanto côncavo, com declives superiores a $15 \%$. Com isso, há concentração do fluxo e escamento rápido pela encosta, fazendo com que haja maior propensão de atuação dos processos erosivos, tendo uma maior capacidade de transporte de materiais pela vertente. A unidade possui área de $193,73 \mathrm{~km}^{2}$ representando $3,76 \%$ da área total.

A Unidade XVII apresenta declives superiores a $15 \%$, com o plano de curvatura divergente e o perfil de curvatura côncavo. A unidade caracteriza-se em meia encosta, com fluxo disperso em direção as regiões as mais baixas. A unidade apresenta área de $89,61 \mathrm{~km}^{2}$ representando $1,74 \%$ da BHRJ.

A Unidade XVIII com declives superiores a $15 \%$, com plano de curvatura divergente e o perfil de curvatura côncavo. A unidade caracteriza-se por estar no topo de colinas e morrotes, influenciando em um escoamento intenso e atuação dos processos erosivos sobre o relevo. A unidade apresenta área de $188,87 \mathrm{~km}^{2}$ representando $3,66 \%$ da área total da BHRJ. A representação das unidades geomorfométricas XV e XVI, podem ser analisadas conforme a Figura 09.

Figura 09 - Mapa das Unidades Geomorfométricas XVI, XVII e XVIII

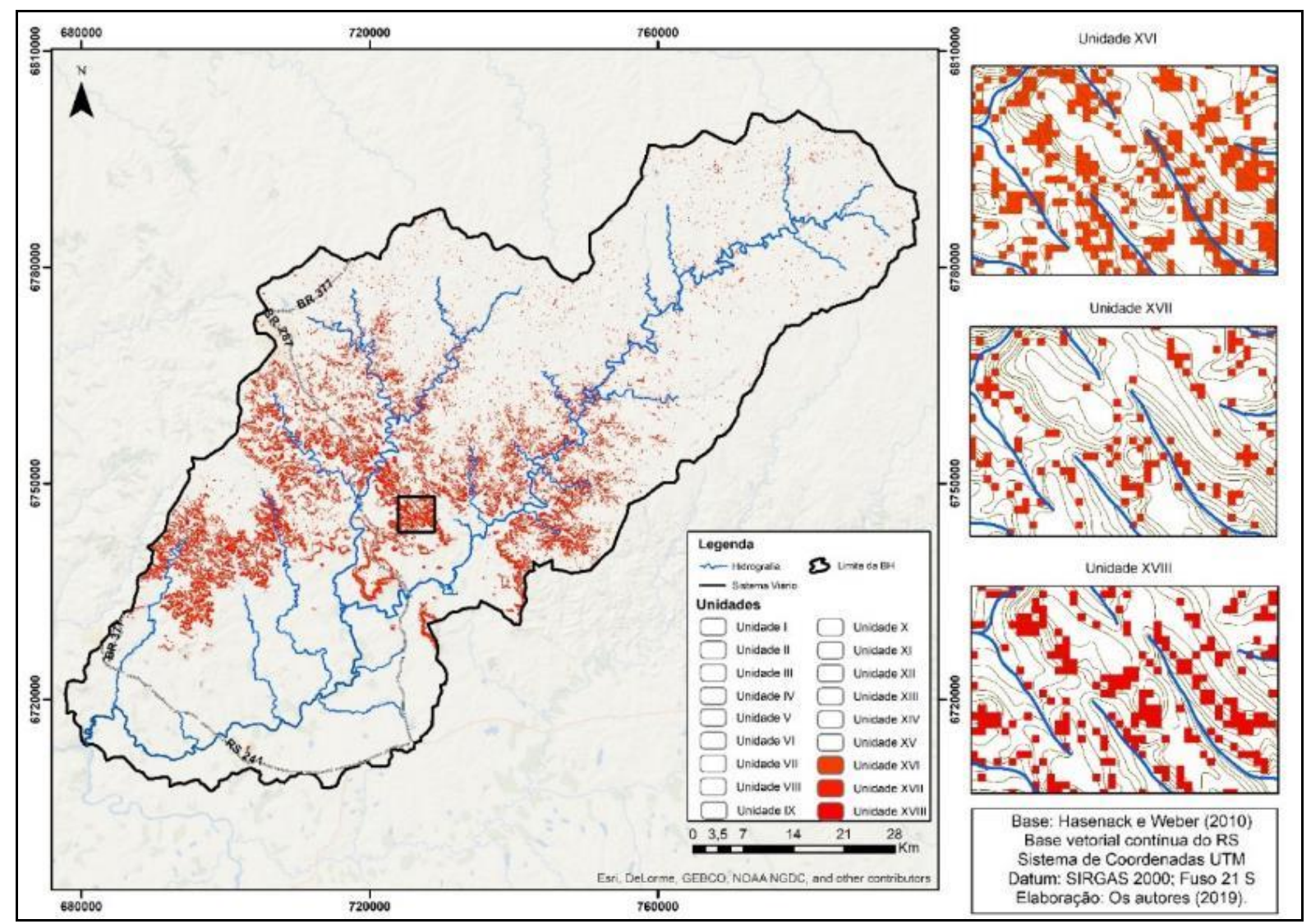

Fonte: Os autores. 
As Unidades XVI, XVII e XVIII apresentam-se em declives que caracterizam a transição entre diferentes compartimentações geomorfológicas no Rio Grande do Sul, o Planalto Meridional ao norte da bacia hidrográfica e a Depressão Central.

$\mathrm{Na}$ Figura 10, podemos visualizar a porção de transição entre as Unidades Geomofológicas na BHRJ, caracterizando as Unidades Geomorfométricas XVI, XVII e XVIII.

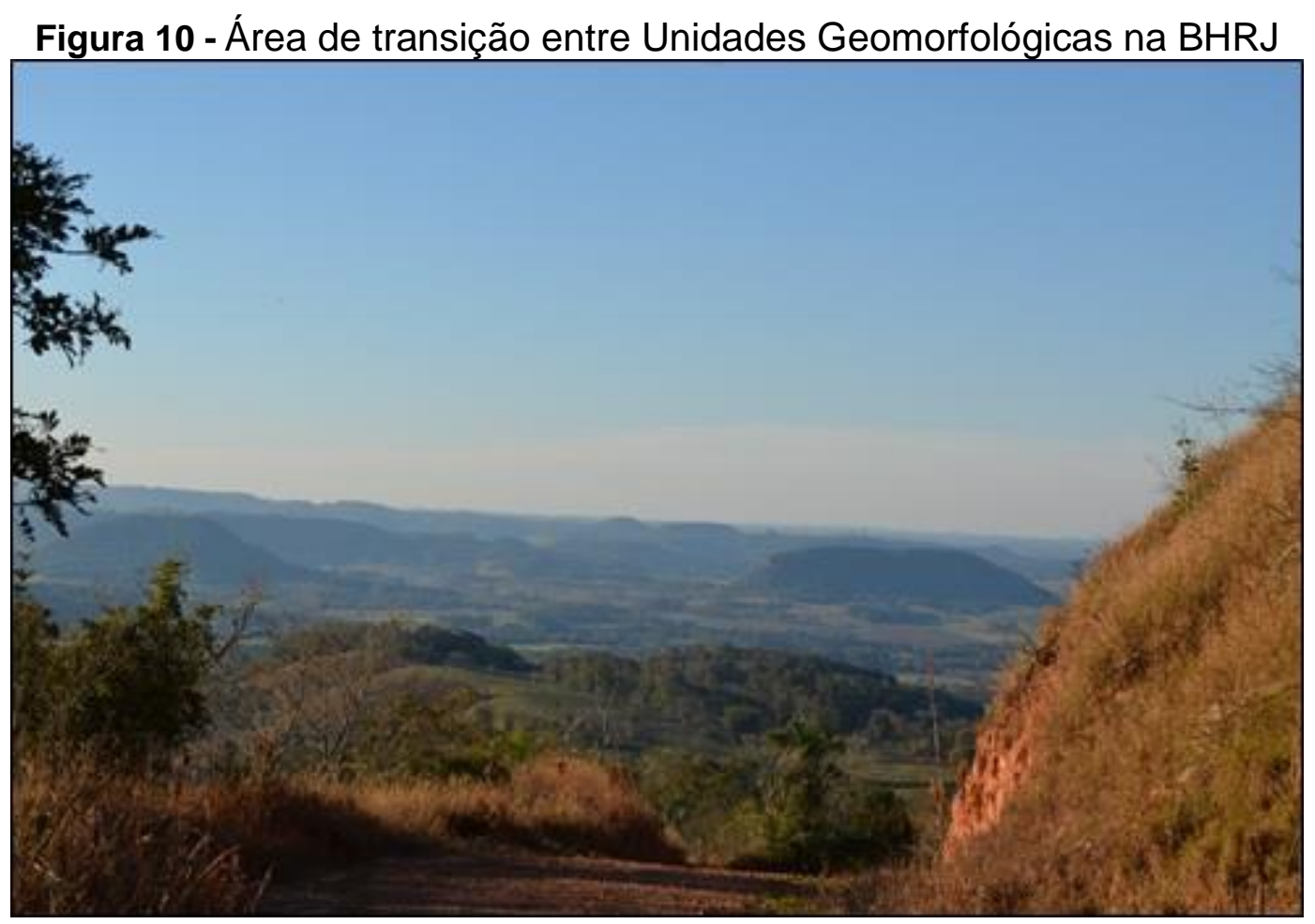

Fonte: Os autores. Coordenadas: S29³1'15.96"; W54³9'13.13"; Localidade: Jaguari-RS

\section{Considerações Finais}

Com a caracterização das unidades geomorfométricas, a partir de técnicas de geoprocessamento, interpolando os parâmetros topográficos (altitude, declividade e curvatura de vertentes), possibilita definir as áreas susceptíveis aos processos erosivos atuantes no relevo.

$\mathrm{Na}$ visualização dos mapas temáticos, é possível identificar através dos quadros demonstrativos das unidades, a correlação dos parâmetros fixos interpolados em SIG, que acabam marcando as feições geomorfológicas na área de estudo. $\mathrm{Na} \mathrm{BHRJ}$, foram identificadas 24 unidades geomorfométricas, que foram reagrupadas em 18 unidades mais representativas, utilizando como parâmetro para o processo, o plano de curvatura.

A compartimentação geomorfométrica possibilita realizar uma caracterização quantitativa e precisa do relevo, através dos parâmetros topográficos, fazendo 
entender a atuação dos processos determinantes para a alteração na forma da paisagem.

A proposta de compartimentação geomorfométrica na BHRJ obteve resultados satisfatórios, sendo que em locais de diferentes características geomorfológicas, os declives foram facilmente reconhecidos. Salvo que, em outros trabalhos a serem desenvolvidos nessa temática, é necessário obter os parâmetros e analisa-los, para que não haja erro na correlação espacial.

\section{REFERÊNCIAS}

Guadagnin, P.M.A; Trentin, R. Compartimentação Geomorfométrica da Bacia Hidrográfica do Arroio Caverá - RS. Geo UERJ. Rio de Janeiro - Ano 16, ํㅡ. 25, v. 1, 1ำ semestre de 2014, pp.183-199. ISSN: 1415-7543 E-ISSN: 1981-9021.

IWAHASHI, J.; PIKE, R. J. Automated classifications of topography from DEMs by an unsupervised nested236. Revista Brasileira de Geomorfologia, São Paulo, v.16, n.2, (AbrJun) p.219-237, 2015 means algorithm and a three-part geometric signature. Geomorphology 86 (3-4): 409-440, 2007.

Rocha, C.H.B. Geoprocessamento Tecnologia. Transdisciplinar Juiz de Fora. Minas Gerais. Edição do Autor. 2000.

SCCOTI, A. A. V. Zoneamento Geoambiental da Bacia Hidrográfica do Rio Ibicuí da Armada-RS: Potencialidades e Suscetibilidade. 2015. 151p. Dissertação (Mestrado em Geografia) - Universidade Federal de Santa Maria, Santa Maria, 2015.

SCHIRMER, G. J. Zoneamento Geoambiental da Quarta Colônia - Rio Grande do Sul. 2015. 253f. Tese (Doutorado em Geografia) -Universidade Federal de Santa Maria, Santa Maria, 2015.

SILVEIRA, Claudinei Taborda da. Análise digital do relevo na predição de unidades preliminares de mapeamento de solos: integração de atributos topográficos em sistemas de informações geográficas e redes neurais artificiais. Tese (Doutorado) Universidade Federal do Paraná, Setor de Ciências da Terra, Programa de Pós-Graduação em Geografia. - Curitiba, 2010.

SILVEIRA, R.M.P.; SILVEIRA, C.T., OKA-FIORI, C. Emprego de técnicas de inferência espacial para identifi cação de unidades de relevo apoiado em atributos topográficos e árvore de decisão. Revista Brasileira de Geomorfologia, v. 15, n. 01, p. 87-101, 2014a.

SIRTOLI, A. E.; SILVEIRA, C. T.; MONTOVANI, L. E.; SIRTOLI, A. R. A.; OKAFIORI, C. Atributos do relevo derivados de modelo digital de elevação e suas relações com solos. Scientia agraria, v.9, n.3, p.317-329, 2008.

SOUSA JUNIOR, J.G.A.; DEMATTÊ, J.A.M. Modelo digital de elevação na caracterização de solos desenvolvidos de basalto e material arenítico. Revista Brasileira de Ciência do Solo, v.31, p.449-456, 2008.

STRAHLER, A. N. Dynamic basis of Geomorphology. Geol. Soc.America Bulletin. 1952.

VASCONCELOS, V. et al. Sistema de Classificação Geomorfométrica Baseado em uma Arquitetura Sequencial em Duas Etapas: Árvore de Decisão e Classificador Espectral, 
No Parque Nacional Serra da Canastra. Revista Brasileira de Geomorfologia, v.13, n.2, (Abr-Jun) p.171-186, 2012.

ZEVENBERGEN, L.W.; THORNE, C.R. Quantitative Analysis of Land Surface Topography. Earth Surface Processes and Landforms, v.12, p.47-56, 1987.

\section{NOTAS DE AUTOR}

\section{CONTRIBUIÇÃO DE AUTORIA}

Vinícius Silveira dos Santos - Concepção. Coleta de dados, Análise de dados, Elaboração do manuscrito, revisão e aprovação da versão final do trabalho

Luís Eduardo de Souza Robaina -Coleta de dados Participação ativa da discussão dos resultados; Revisão e aprovação da versão final do trabalho.

Romario Trentin -Coleta de dados Participação ativa da discussão dos resultados; Revisão e aprovação da versão final do trabalho.

\section{FINANCIAMENTO}

O presente trabalho foi realizado com apoio da Coordenação de Aperfeiçoamento de Pessoal de Nível Superior Brasil (CAPES) - Código de Financiamento 001.

O presente trabalho foi realizado com apoio da Conselho Nacional de Desenvolvimento Científico e Tecnológico

- Bolsa Pesquisador.

\section{CONSENTIMENTO DE USO DE IMAGEM}

Não se aplica

\section{APROVAÇÃO DE COMITÊ DE ÉTICA EM PESQUISA}

Não se aplica

\section{CONFLITO DE INTERESSES}

Não se aplica

\section{LICENÇA DE USO}

Este artigo está licenciado sob a Licença Creative Commons CC-BY. Com essa licença você pode compartilhar, adaptar, criar para qualquer fim, desde que atribua a autoria da obra.

\section{HISTÓRICO}

Recebido em: 15-05-2019

Aprovado em: 19-05-2020 